\title{
Seismic vulnerability assessment of clustered historical centers: fragility curves based on local collapse mechanisms analyses
}

\author{
S. Taffarel, M. Caliman, M.R. Valluzzi, F. da Porto \& C. Modena \\ University of Padova, Department of Civil, Environmental and Architectural Engineering, 35131 Padova, \\ Italy
}

\begin{abstract}
Protection and preservation of minor historical centres against earthquakes effects are not trivial tasks, particularly in the cases, quite common, of complex aggregate buildings. The paper aims at evaluating the seismic vulnerability of historical clustered buildings on a urban scale, through the analysis of local collapse mechanisms, carried out with a parametric approach. This procedure is applied to four historical centres of L'Aquila province struck by the 2009 earthquake. The identification of the significant parameters is related to the definition of representative typologies within the city centres. Each typology is characterized by recurring features, mainly recognizable with a survey performed outside the buildings. After the identification of the relevant aspects, local mechanisms of collapse analyses are carried out, by varying the parameters between defined range of values, in order to take into account possible uncertainties in the data collection. A set of fragility curves for each identified typology is defined and the obtained results are compared to the damage data gathered in the post-earthquake phase for the buildings. This approach allows for possible extensions to buildings that may be included in the typology categories here defined.
\end{abstract}

\section{INTRODUCTION}

Italian minor historical centres are usually characterized by clustered buildings, defining very complex urban textures. For this reason, their protection and preservation against damages that possible earthquakes could cause are topical tasks. Several studies about this topic has been carried out by Italian and international research groups, aiming at mitigating the seismic risk by defining suitable methodologies for the seismic vulnerability assessment on a territorial scale (Irizarry et al., 2010) (Pagnini et al. 2008) (Cattari et al., 2004).

The complexity of the study of historical clustered buildings seismic vulnerability suggests the possibility to identify representative common aspects (related to geometry, type of structural components, vulnerable elements) that may constitute significant parameters characterizing specific classes of building typologies (Munari et al., 2010) (Giovinazzi et al. 2001), to be analysed with local collapse mechanisms. This parametric approach can be then extended at urban scale for predictive vulnerability analyses.

This methodology was applied on four historical centres of L'Aquila province struck by the L'Aquila earthquake of April 6, 2009, namely: Castelvecchio
Calvisio, Castel del Monte, Villa Santa Lucia degli Abruzzi and Santo Stefano di Sessanio. Clustered buildings in the centre of L'Aquila were also analysed in order to compare results referred to different structural typologies.

The adopted procedure allows defining the propensity of historical masonry clustered buildings to suffer damages due to earthquakes, on the basis of rapid surveys. The first phase concerns the preliminary knowledge of the historical centre: detailed historical and urban analyses were performed in order to acquire information on the area, the recurrent constructive techniques and the urban and architectural features. Data gathered during inspections were included in specific forms and statistically analysed to identify the most common buildings features. Therefore, twenty buildings typologies representing the analysed Structural Units (SU) were defined.

The subsequent implementation of simple overturning local mechanisms of collapse provided the analysis of the response of each typology under seismic actions, according to the kinematic approach. This approach is based on the evaluation of the horizontal action trend that the structure is progressively able to withstand during the evolution of the mechanism (NTC 2008, Circolare n.617). Then, fragility curves, which describe the probability of a structure to reach or exceed a certain damage level 
considering various values of peak ground acceleration, are defined.

This methodology can be extended to other municipalities areas and historical city centers characterized by similar architectural and typological features. Fragility curves are useful tools to assess the seismic vulnerability of defined typologies and obtained assessments can be easily represented through vulnerability maps.

\section{AREA DESCRIPTION}

\subsection{General overview}

The analysed minor historical centres (Figure 1) have quite homogeneous features: Castelvecchio Calvisio, Villa Santa Lucia degli Abruzzi, Castel del Monte and Santo Stefano di Sessanio are small medieval towns located on the eastern side of the Apennines. Defensive needs led to the development of a urban morphology typically constituted by small houses which are closed one to another, forming a compact structure (the so called "case-mura"). During the centuries, the original urban textures were modified, but some typical features still remains: stone walls, buttress arches, external stairs, covered passages, etc.

The buildings in the city of L'Aquila (Figure 2) have different features, consistent with the monumental building typology called "palazzo", having huge dimensions and high architectural value.

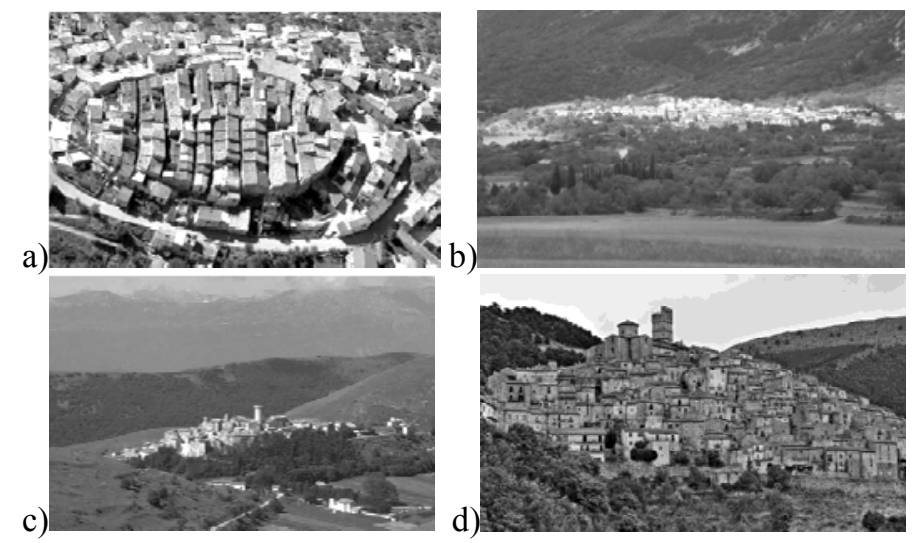

Figure 1: Aerial view of Castelvecchio Calvisio (a), Villa Santa Lucia degli Abruzzi (b), Santo Stefano di Sessanio (c) and Castel del Monte (d).

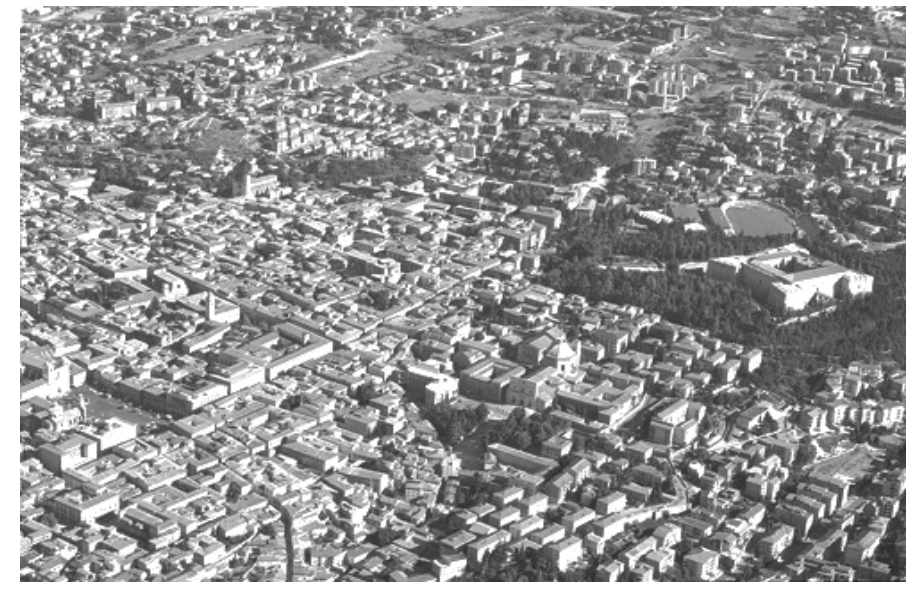

Figure 2: Aerial view of L'Aquila

\subsection{The 2009 earthquake and the reconstruction plans}

The studied area has severe seismic hazard and was struck in the past by a number of destructive earthquakes. The earliest documentation of an earthquake sequence in the Apennines dated back to 1348 and 1349; in 1349 the seismic event almost completely destroyed the city of L'Aquila. Since then, the area suffered a lot of damage due to other strong earthquakes. The most recent one occurred on April $6^{\text {th }}, 2009$, having a local magnitude $\mathrm{Ml}=5.8$ and a moment magnitude $\mathrm{Mw}=6.32$. The main shock developed at a focal depth of about $8.3 \mathrm{~km}$. The earthquake hit an extensive area, involving the city of L'Aquila and its province, including many small historical centers located on the Gran Sasso Region, and part of the territory in the provinces of Pescara, Teramo and Chieti, affecting any kind of soil and structure (Marson et al. 2013).

Therefore, a strategic plan was adopted in order to define univocal solutions to face the post-emergency phases in the whole area. Reconstruction plans were defined, involving some minor historical centers. Each plan describes management and economic planning tools for buildings repairs and reconstructions, and defines actions and interventions to ensure the safety of each area and to reduce their seismic vulnerability (DCD, 2010). The reconstruction plans of Castel del Monte, Castelvecchio Calvisio, Santo Stefano di Sessanio and Villa Santa Lucia degli Abruzzi were developed by adopting specific pilot projects, involving buildings located in each municipality (AA. VV, 2013 and 2014).

\section{TYPOLOGICAL CLASSIFICATION}

\subsection{Typologies identification}

The identification of significant parameters is strictly related to the identification of representative typologies within the historical centers. Typologies have recurrent characteristics recognizable from 
buildings external observation (e.g. geometrical and/or structural features, vulnerability elements), performed by carrying out rapid surveys. The method allows extending the results to buildings related to the typologies previously defined on the basis of few data/parameters, even not directly detected.

Each clustered building was here studied supposing its historical evolution and identifying homogeneous SU. A total of forty-two SU were detected within the five analyzed municipalities. Moreover, geometrical, photographical, structural and constructive surveys were carried out. Those data were used for the typological analysis, whose purpose was the detection of recurrent characteristics among the analyzed SU. The collected data referred to: number of floors, prevalent vertical structures, prevalent horizontal structures, inter-storey height, wall thickness, planimetric module, vaults span, façade openings and floors bearing direction. The SU were then subdivided taking into account the number of out-ofground floors and prevalent vertical and horizontal elements: twenty structural typologies were identified, named by letters (A-V). All SU were made of ashlars, except for those located in L'Aquila, which had different vertical structures (typologies F, G, O, $\mathrm{P}, \mathrm{Q}$ and $\mathrm{R}$ ). The typologies were defined by grouping prevalent horizontal structures depending on their weight (light, heavy, very heavy), which is one of the parameters affecting the kinematic analysis, and on their stiffness. Vaults were analyzed separately, because of their weight (quite high compared to the other horizontal diaphragms) and their horizontal thrust component. Inter-storey height and walls thickness values were assigned to each typology. Values were obtained by averaging the values measured for each level separately: the ground floor (often larger than the others), the middle floors and the fourth floor, usually having different characteristics from the others. In particular, the fourth floor was often an attic; therefore, its height was significantly lower than the one of the other levels. Other geometric and structural features were established by averaging the values obtained from the statistical analysis within each typology. The friction forces between walls and horizontal structures were not considered, since the assignment of a realistic value of the friction coefficient requires extensive studies on buildings, which are in contrast with a simplified and quick approach. The twenty detected typologies are graphically represented in Figure 3.

Based on the performed analyses and the obtained results, the structural typologies identified for the minor historical centers (Castel del Monte, Castelvecchio Calvisio, Santo Stefano di Sessanio and Villa Santa Lucia degli Abruzzi) were almost similar; it was then possible to conduct a unified study and to extend the results to other buildings belonging to centers having similar features. For this study, the assignment of a planimetric module to each typology was not significant. Preliminary kinematic analyses showed that its variation (from which the influence area of the horizontal structure on the vertical wall depends) did not produce significant variations in the horizontal load multiplier of the mechanism, so it was excluded from the analysis.
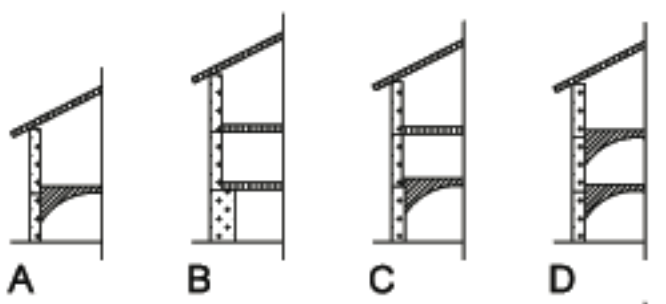

D
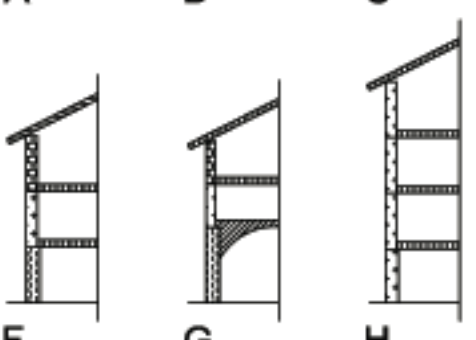

$\mathrm{H}$

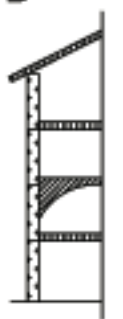

I
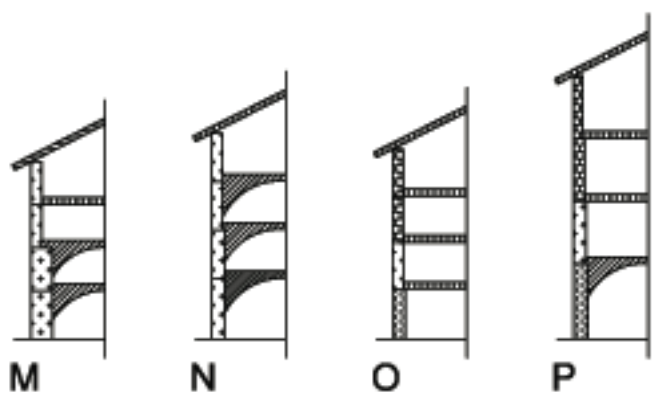

P
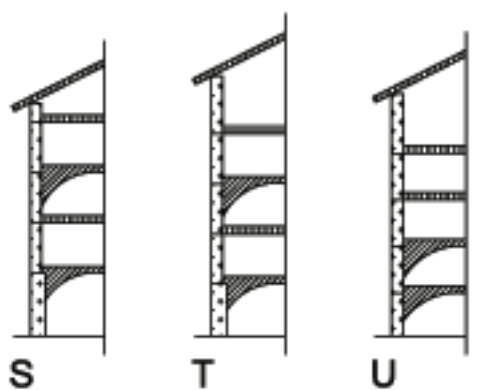
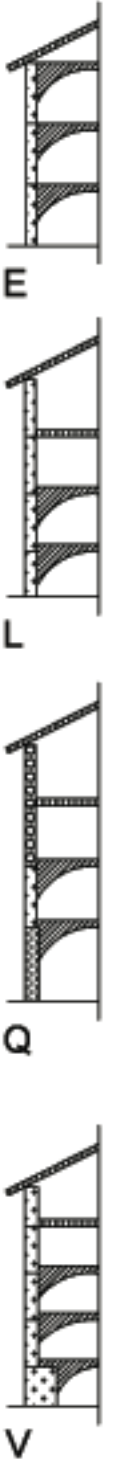

E

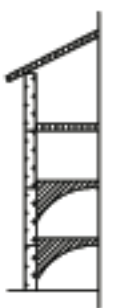

L

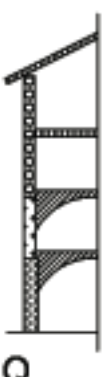

Q

Figure 3: Typologies identified in the study.

\subsection{Parameters identification}

After the typological analysis, parameters that significantly influence the behavior of the aggregate buildings in relation to the local responses that they could manifest during earthquakes must be evaluated. In particular, analyses were focused on the overturning of walls basically resting on the ground, and on the overturning of the upper parts of the walls. For each defined typology, the analysis of local collapse mechanisms taking into account various hinge levels was carried out. Variable parameters are shown in Table 1. 
Table 1: Parameters adopted in the study.

\begin{tabular}{|c|c|c|}
\hline Parameter & Variation & Scheme \\
\hline $\begin{array}{l}\text { Inter-storey } \\
\text { height }\end{array}$ & $\begin{array}{l} \pm 1,00 \mathrm{~m}, \text { ground } \\
\text { floor/upper levels }\end{array}$ & f \\
\hline Wall thickness & $\begin{array}{l} \pm 0,10 \mathrm{~m} \text {, ground } \\
\text { floor/upper levels }\end{array}$ & \\
\hline Vault rise & $\pm 0,50 \mathrm{~m}$ & $\square \longdiv { \square }$ \\
\hline Vault typology & $\begin{array}{l}\text { Cross vault or } \\
\text { barrel vault }\end{array}$ & $\rightarrow 5$ \\
\hline $\begin{array}{l}\text { Horizontal } \\
\text { structure ty- } \\
\text { pology }\end{array}$ & $\begin{array}{l}\text { Very heavy, } \\
\text { heavy, light }\end{array}$ & 第 \\
\hline $\begin{array}{l}\text { Bearing direc- } \\
\text { tion }\end{array}$ & $\begin{array}{l}\text { Parallel or or- } \\
\text { thogonal to the } \\
\text { wall }\end{array}$ & \begin{tabular}{|l|}
2 \\
\end{tabular} \\
\hline Plan module & $\begin{array}{l}\text { The most fre- } \\
\text { quent }\end{array}$ & $\vec{\square}$ \\
\hline $\begin{array}{l}\text { Façade open- } \\
\text { ings percent- } \\
\text { age }\end{array}$ & $\begin{array}{l}\text { Four ranges were } \\
\text { defined }\end{array}$ & 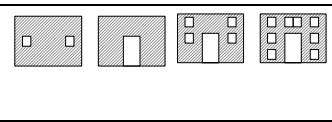 \\
\hline
\end{tabular}

In order to better calibrate the following analyses, overturning mechanisms were initially calculated only for typology D, constituted by three stories, vaults on two levels and timber roof. The homogeneous wall thickness and inter-storey height allowed identifying the parameters that can be considered significant for the analysis. To this aim, the values of the horizontal load multiplier were compared by varying the identified parameters. To evaluate the influence of each parameter, they were singularly changed, and later combined one to the other.

As mentioned before, some of these parameters did not significantly influence the results, since the horizontal load multiplier was substantially the same despite the variation of the parameters. Planimetric module and the façade openings percentage were considered irrelevant parameters for this study and thus excluded from the analysis.

\section{A PROCEDURE FOR SEISMIC VULNERABILITY ASSESSMENT}

\subsection{Local collapse mechanisms analysis}

The systematic variation of parameters identified as relevant was carried out. The procedure took into account the possible inherent uncertainty of the parameters, due to the impossibility of investigating in detail the analyzed buildings. Firstly, the study was carried out analyzing single parameters, which were then combined taking into account all possible configurations. In some cases, some parameters were not considered if they did not typify the analysed ty- pology. This procedure permitted the definition of a set of capacity curves for each typology and for each analyzed local collapse mechanism. Some local mechanisms for typologies including vaulted structures on many floors had a negative coefficient of activation, certainly related to some simplifications assumed in the analysis. A negative activation coefficient, in fact, represents the activation of the collapse mechanism in static conditions, i.e., without assuming a seismic input. However, this situation does not actually occur in the real case, because vertical loads and vaults springing point should be different from the average values considered for the typology. Therefore, those mechanisms were not considered in the analysis. Moreover, more detailed analyses considering also the effectiveness of tie rods as a variable parameter could be performed after the identification of the most vulnerable typologies, in order to obtain results which are less conservative and closest to the real configuration. For safety purposes, the possible presence of tie rods was not considered in this study, since their effectiveness is unknown.

\subsection{Damage levels and elastic response spectrum}

Once capacity curves were obtained, appropriate levels of damage were established. In case of nonlinear kinematic analysis, levels of damage were related essentially to the structure displacement that annulled horizontal loads. The levels of damage were then defined according to (Lagomarsino et al., 2014), as shown in Table 2 and Figure 4.

Table 2: Definition of levels of damage.

\begin{tabular}{|l|l|}
\hline Minor & $\mathrm{DL} 1=0,7 \cdot \mathrm{ds}^{*}$ \\
\hline Moderate & $\mathrm{DL} 2=\mathrm{ds}^{*}$ \\
\hline Extensive & $\mathrm{DL} 3=0,25 \cdot \mathrm{d} 0^{*}$ \\
\hline Collapse & $\mathrm{DL} 4=0,40 \cdot \mathrm{d} 0^{*}=\mathrm{du}^{*}$ \\
\hline
\end{tabular}

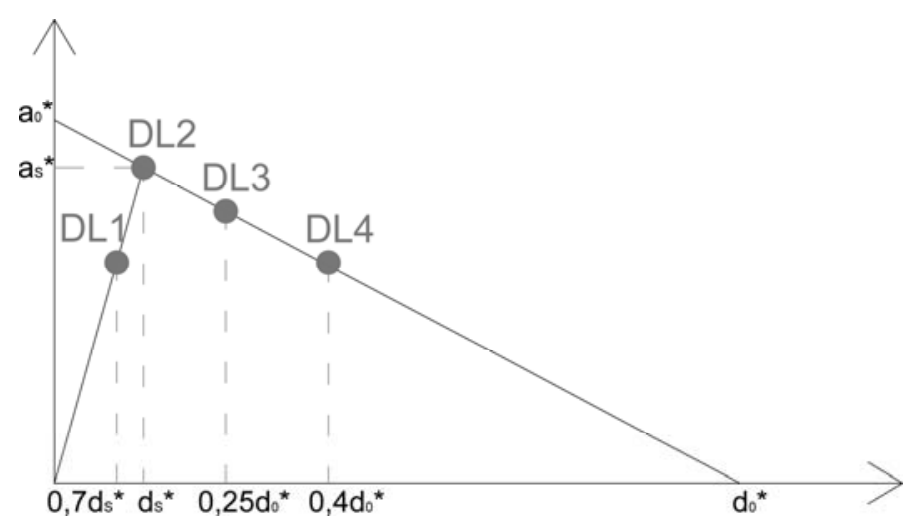

Figure 4: Representation of the damage levels.

Due to uncertainty and unpredictability of seismic intensity, different values of peak ground acceleration were considered in the analysis, in order to ana- 
lyze as many cases as possible. The municipalities under study are characterized by different seismic parameters. Since the values of their peak ground acceleration oscillate close to $0.25 \mathrm{~g}$, a range of acceleration between $0,00 \mathrm{~g}$ and $0,50 \mathrm{~g}$ was chosen, considering $0.25 \mathrm{~g}$ as average value. This range is divided into intervals of $0.05 \mathrm{~g}$ each, thus obtaining ten different PGA levels. Despite considered sites have various soil and topographic categories, for educational purposes soil category A and topographic category T1 were assumed and local soil amplifications were not taken into account. The same procedure can be adopted changing spectrum shape on the basis of different soil and topography categories, varying coefficients related to the stratigraphic amplification $\left(\mathrm{S}_{\mathrm{S}}, \mathrm{S}_{\mathrm{T}}\right.$ and $\mathrm{C}_{\mathrm{C}}$ ) (NTC 2008, Circolare n.617). For the considered PGA values, ten elastic response spectra were obtained (

Figure 5).

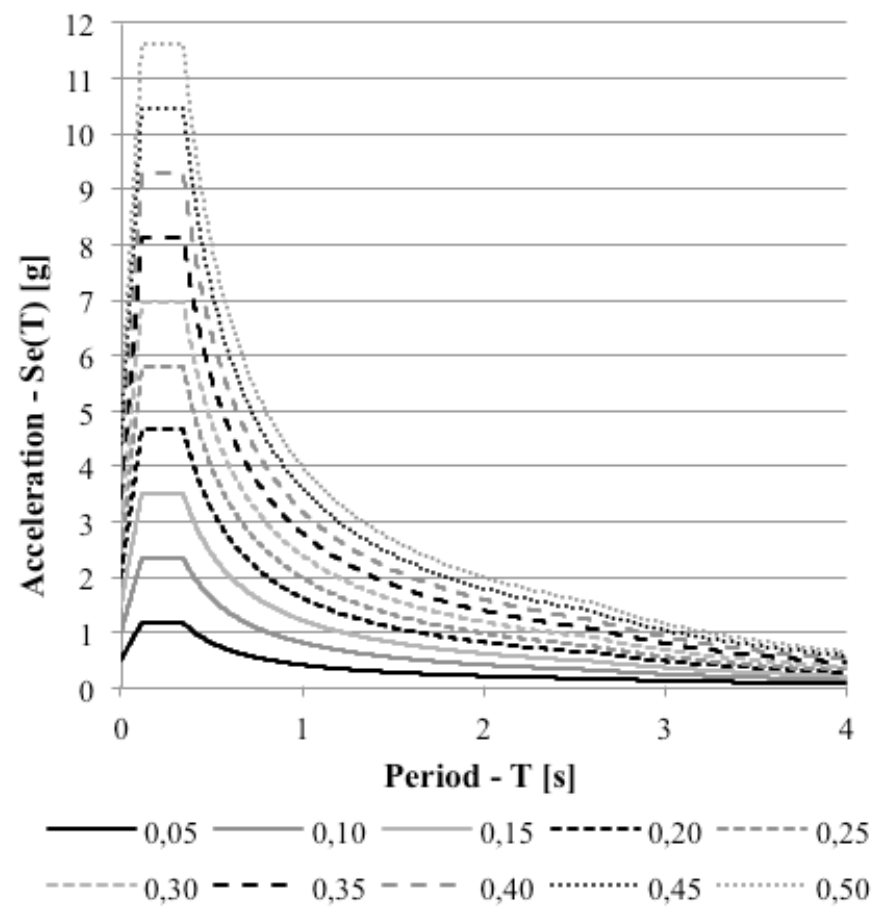

Figure 5: Elastic response spectrum for each PGA value.

\subsection{Fragility curves}

Elastic spectra and capacity curves were adopted to define fragility curves, according to the "CSM Method" proposed by Shinozuka et al. (2000). This method refers to a non-linear static procedure for the definition of the intersection point between the demand and the capacity curves. This point is called "performance point" and represents the maximum expected displacement for each given seismic event. The behavior of the structure (capacity) is represented by the $a^{*}-d^{*}$ curve of the equivalent one-degreeof-freedom system. The expected displacement is determined by identifying the displacement capacity compatible with the seismic demand. This procedure is carried out in the Acceleration-Displacement Response Spectrum (ADRS) plan, thus describing the capacity curve and the response spectrum in terms of spectral acceleration and displacement. In the ADRS plan, response spectrum and capacity curve are respectively called demand spectrum and capacity spectrum. Once the "performance point" is defined, damage (IM) is obtained as the ratio between the displacement due to the seismic demand and the displacement referred to the considered level of damage, and is represented through a lognormal distribution.

Grouping in a single graph the damage values obtained for the different PGAs, the coefficients A and $\mathrm{B}$ defined by the regression line (Figure 6) are obtained. In the ADSR plan the medium demand associated to each level of damage is defined by Equation 1:

$$
\ln \left(S_{d}\right)=A+B \cdot \ln (I M)
$$

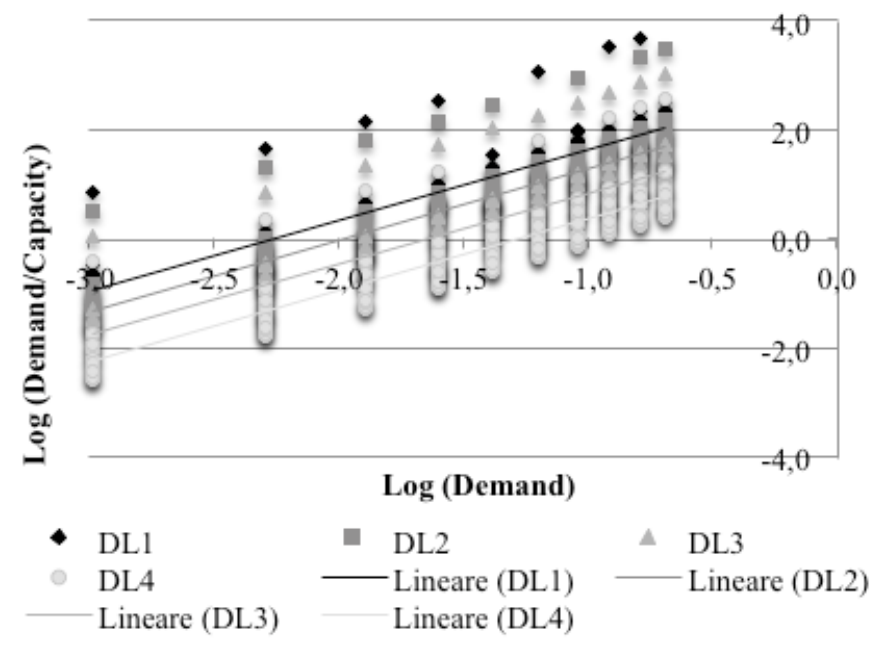

Figure 6: Regression line for Typology A, overturning of the wall substantially resting on the ground.

The fragility curve is then represented by a cumulative lognormal distribution and the exceedance probability is numerically calculated by Equation 2:

$$
f_{D}=\frac{1}{\sqrt{2 \pi} \cdot \varepsilon d} \exp \left[-\frac{1}{2}\left(\frac{\ln d-\lambda}{\varepsilon}\right)^{2}\right]
$$

where: $\lambda=A+B \cdot \ln (\mathrm{IM})$ is the average value evaluated on the regression line corresponding to a given value of IM(PGA); $\varepsilon$ is the dispersion value.

In such a way, fragility curves defining the exceedance probability of each considered level of damage in relation to the PGA, variation were obtained for each typology. Those curves were then further grouped, according to hinge formation levels (Figure 7, Figure 8) 


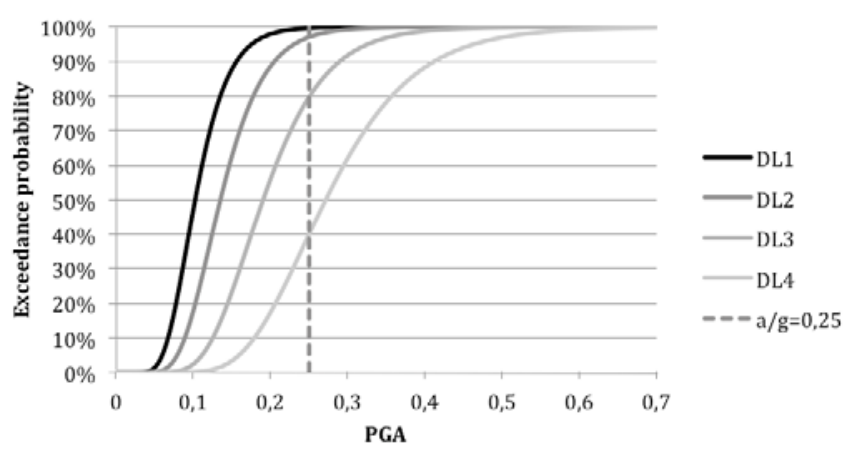

Figure 7: Fragility curves for Typology A, overturning mechanism involving two levels.

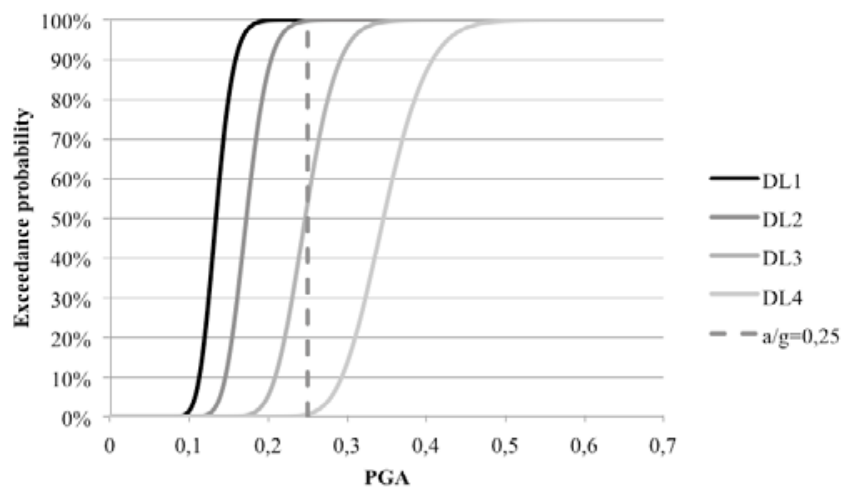

Figure 8: Fragility curves for Typology A, overturning mechanism involving the upper level.

\section{VULNERABILITY ANALYSES}

\subsection{Vulnerability assessment}

The obtained results can also be represented by using histograms, which show each level of damage related to the hinge formation level.Figure 9 shows the damage exceedance probability for the PGA value provided by Italian seismic code $(0.25 \mathrm{~g})$. Values of PGA defining the $100 \%$ exceedance probability are reported in

Figure 10 . The exceedance probability for $\mathrm{a} / \mathrm{g}=0.25$ was also grouped according to hinge formation level, so that typologies results could be compared (

Figure 11).

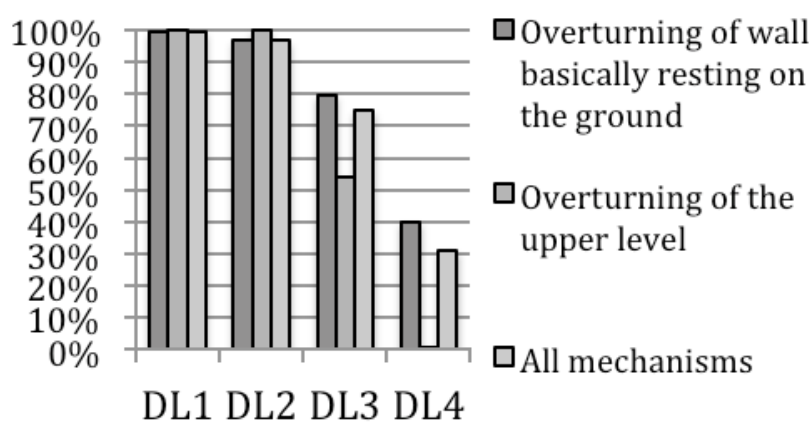

Figure 9: Exceedance probability for $\mathrm{a} / \mathrm{g}=0.25$ - Typology A.

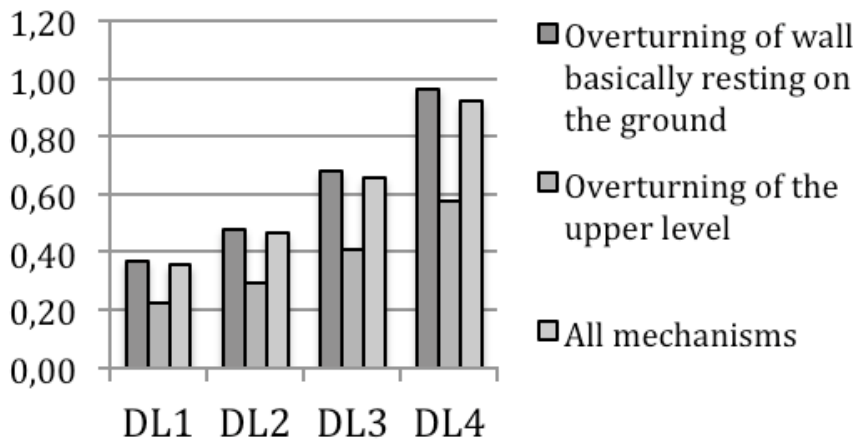

Figure 10: PGA for exceedance probability $100 \%$ - Typology A.

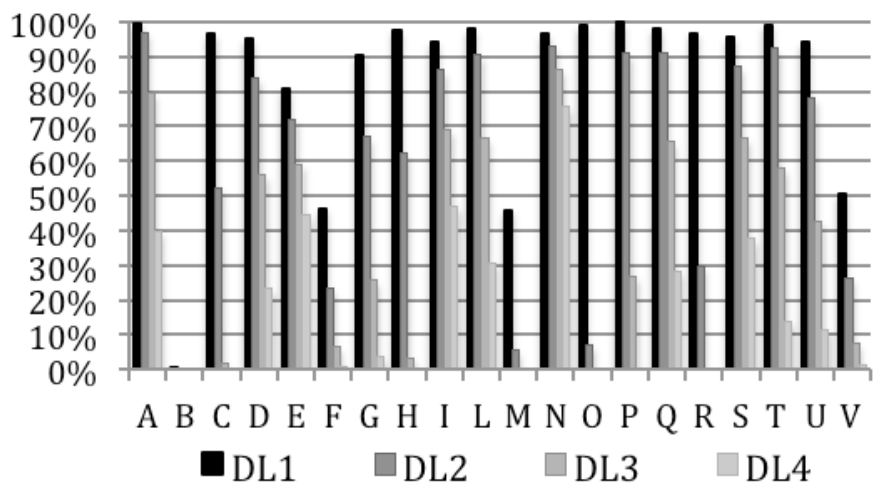

Figure 11: Exceedance probability for $\mathrm{a} / \mathrm{g}=0.25$, overturning of wall basically resting on the ground.

The grouping of fragility curves on the basis of hinge formation levels showed significant differences. As an example, for typology A, which referred to buildings having two stories, vaults at the ground level and timber roof, it is possible to note that the probability of collapse (DL4) was greater when the walls overturning involves a portion which is basically resting on the ground (the damage exceedance probability was $40 \%$ for $\mathrm{a} / \mathrm{g}=0.25$ ), while in case of overturning of the upper level the damage exceedance probability was almost zero (Figure 9). The same observations can be drawn for the level of damage DL3, where the exceedance probability for $\mathrm{a} / \mathrm{g}=0.25$ was $80 \%$ if the overturning involves the entire façade, while it settled down at $55 \%$ if the hinge is located at the upper level. This difference is 
probably due to the presence of vaults at the ground floor, which increase the vulnerability of the building typology, because of their horizontal trust component.

Conversely, typology B referred to thick walls at the ground floor $(1.35 \mathrm{~m})$, reducing their thickness to $60 \mathrm{~cm}$ at the upper levels, and timber horizontal diaphragms for all the levels. The huge wall mass at the lower level and the absence of vaults reduced the probability of suffering a minor damage (DL1) in the case of overturning of the whole façade, while the probability varied between $90 \%$ and $100 \%$ in the case of upper levels overturning.

By observing

Figure 11, it is possible to note that many typologies were characterized by very high values of damage exceedance probability, in particular for damage level DL1. On the contrary, in other cases (for example typology B), the damage exceedance probabilities were very low for each level of damage. This comparison provided a preliminary identification of the most vulnerable typologies.

\subsection{Vulnerability maps}

The obtained fragility curves were then assigned to each SU previously identified (see par. 3.1). The damage exceedance probabilities related to $\mathrm{a} / \mathrm{g}=0.25$ were then graphically represented using a color scale. In this way it was possible to obtain vulnerability maps for each type of overturning mechanism (involving the whole façade or the upper levels) and for each level of damage. As an example, Castel del Monte vulnerability map for overturning mechanism involving the whole façade, considering the level of damage DL3, is shown in

Figure 12 . The analyzed structural units having a very low probability of suffering extensive damage are about $50 \%$, while the remaining ones have damage exceedance probabilities ranging between $40 \%$ and $70 \%$. SU reported in

Figure 12 represent typologies $\mathrm{S}, \mathrm{T}$ and $\mathrm{U}$, which relate to five floors, vaults on two levels (first and third levels for typologies S and T; first and second levels for typology $U$ ) and slender walls.

In order to validate the procedure, a qualitative comparison considering damage information collected after the post-earthquake phases was carried out. A first comparison was referred to crack patterns, by examining whether cracks indicating the activation of an overturning mechanism coincide to an high probability of activation of the same local mechanisms for the corresponding typology. As an example, horizontal cracks identified at the base of top floors in Villa Santa Lucia degli Abruzzi aggregate building (

Figure 13) indicated that the overturning mechanism of the upper floor was activated. In this case, there was a good comparison with results obtained by adopting the proposed methodology, since the exceedance probability for minor-moderate damage levels (DL1, DL2) increased proportionally to the height of hinge formation, but never reached collapse (DL4).

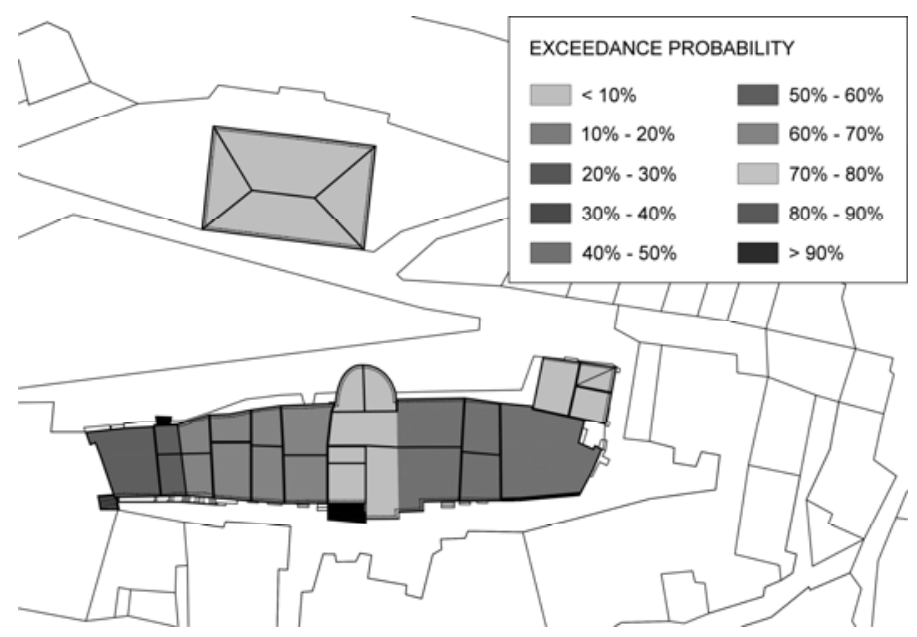

Figure 12: Castel del Monte vulnerability map for overturning mechanism of the whole facade and DL3.

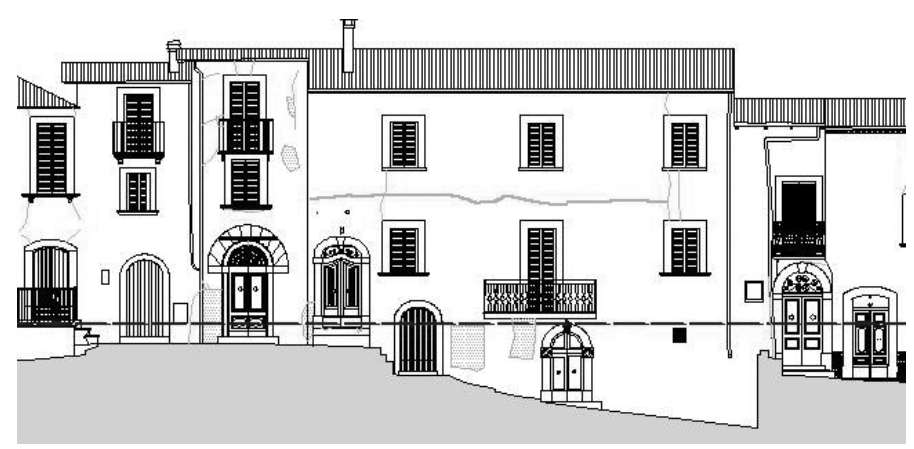

Figure 13: Villa Santa Lucia degli Abruzzi crack pattern.

A further qualitative comparison considering reconstruction plans "fitness for use assessment" tables was carried out. The tables provided use and access restrictions according to the AeDES (First Level form for safety assessment, damage investigation, prompt intervention for ordinary buildings in the post-earthquake emergency) classification, where letter "A" identifies safe buildings, and letter "E" identifies unsafe ones (Civil Protection, 2010). In many cases, considering the PGA level of L'Aquila seismic event, buildings identified by letter "E" corresponded to typologies characterized by high damages exceedance probabilities. As an example, SU in Castel del Monte, classified by adopting letter "E", referred to damage exceedance probabilities greater than other SU located in the same municipality. The study was carried out by adopting typological and probabilistic analyses, therefore some discrepancies between the real situation and assessment obtained by vulnerability maps were possible and acceptable. The fact that not all SU 
characterized by high damage exceedance probability suffered such level of damage is justified by boundary conditions. The extension of damage suffered by the structure in the real situation depends on several variables: adjacent buildings that prevented the activation of a certain mechanism and favor another, discontinuities in wall materials, quality of connections between walls and between walls and floors, earthquake direction, etc.

\section{CONCLUSIONS}

The applied methodology, involving the definition of recurrent building typologies, the identification of relevant parameters and the definition of appropriate levels of damage, allows obtaining suitable fragility curves for the identified typologies, starting from rapid surveys performed from outside the buildings. The subdivision based on typologies and hinge formation level provides fragility curves for professionals and local technicians to be used in extended areas of the historical center. Fragility curves become useful tools to provide preliminary vulnerability assessments, evaluating the propensity to damage occurrence and establishing appropriate levels of expected damage for each considered PGA.

The results obtained for the buildings here analyzed usually match the damage patterns observed on-site after the seismic event; good correlations are also obtained by comparing these results to use and access restrictions.

\section{ACKNOWLEDGEMENT}

The authors wish to thank Universities and Institutes involved in the reconstruction plans of Castel del Monte, Castelvecchio Calvisio, Santo Stefano di Sessanio and Villa Santa Lucia degli Abruzzi (AQ). The efforts of current and former PhD students and staff of the University of Padova, in field of damage inspection on buildings and data collection are also acknowledged.

\section{REFERENCES}

AA.VV University of Padova, Construction Technologies Institute, Politecnico of Milano and University of Roma "La Sapienza" (2014), Reconstruction plans of Castelvecchio Calvisio and Villa Santa Lucia degli Abruzzi [In Italian].

AA.VV University of Padova, Construction Technologies Institute, Politecnico of Milano and University of Roma "La Sapienza" (2014), Reconstruction plans of Castel del Monte and Santo Stefano di Sessanio [In Italian].

Cattari, S., Curti, E., Giovinazzzi, S., Lagomarsino, S., Parodi, S., (2004). Un modello meccanico per l'analisi di vulnerabilità del costruito in muratura a scala urbana. In A.N.I.D.I.S 2004, L'ingegneria Sismica in Italia, Genova, Italia, Conference Proceedings [In Italian].
Civil Protection (2010) - AeDES "First Level form for safety assessment, damage investigation, prompt intervention for ordinary buildings in the post-earthquake emergency". [In Italian]. Available at: http://www.protezionecivile.gov.it/jcms/it/view_pub.wp?co ntentId=PUB5.

da Porto, F., Munari, M., Prota, A.and Modena, C. 2012. Analysis and repair of clustered buildings: Case study of a block in the historic city centre of L'Aquila (Central Italy). In Construction and building materials 38 (2013), Elsevier.

DCD n.3/2010, Commissario Delegato per la Ricostruzione (2010). Linee di indirizzo strategico per la ripianificazione del territorio, [In Italian].

Giovinazzi, S., Lagomarsino, S. (2001). Una metodologia per l'analisi di vulnerabilità sismica del costruito. In $X$ Congresso Nazionale "L'ingegneria Sismica in Italia”, Potenza-Matera [In Italian].

Irizarry, J., Lantada, N., Pujades, L.G., Barbat, A.H., Goula, X., Susagna, T., Roca, A. (2010). Ground-shaking scenarios and urban risk evaluation of Barcelona using the Risk-UE capacity spectrum based method. In Bulletin of Earthquake Engineering 01/2011; 9(2):441-466. DOI: 10.1007/s10518010-9222-6.

Lagomarsino, S., Cattari, S., (2014). PERPETUATE guidelines for seismic performance-based assessment of cultural heritage masonry structures. In Bulletin of Earthquake Engineering (2015), 13:13-47, DOI 10.1007/s10518-014-96741

Marson, C., Taffarel, S., Bettiol, G., Munari, M., Modena, C. , Cialone, G., Cifani, G., Mannella, A. and Petracca, A. (2013). Sviluppo dei Piani di Ricostruzione di borghi dell'aquilano colpiti dal sisma del 6 aprile 2009. In A.N.I.D.I.S 2013, L'ingegneria Sismica in Italia, Padova, Italia, Conference Proceedings [In Italian].

Ministero delle Infrastrutture e dei Trasporti (2008). NTC2008 - Norme tecniche per le costruzioni. D.M. 14/01/2008 [In Italian].

Ministero delle Infrastrutture e dei Trasporti (2009). Circolare esplicativa 02/02/2009 n. 617. Istruzioni per l'applicazione delle «Nuove norme tecniche per le costruzioni». D.M. 14/02/2008 [In Italian].

Munari, M., Valluzzi, M.R., Cardani, G., Anzani, A., Binda, L., Modena, C. (2010), Seismic vulnerability analyses of masonry aggregate buildings in the historical centre of Sulmona (Italy). In 13th International Conference SFR 2010, Edinburgh, UK.

Pagnini, L., Vicente, R., Lagomarsino, S., Varum, H., (2008). A mechanical method for the vulnerability assessment of masonry buildings. In The 14 Th World Conference on Earthquake Engineering October 12-17, 2008, Beijing, China, Conference proceedings.

Shinozuka, M., Feng, M. Q., Kim, H. K. and Kim, S. H., (2000a). Nonlinear static procedure for fragility curve development. In Journal of Engineering Mechanics-Asce, 126, 12, 1287-1295.

Shinozuka, M., Feng, M. Q., Lee, J. and Naganuma T., (2000b), Statistical analysis of fragility curves. In Journal of Engineering Mechanics-Asce, 126, 12, 1224-1231. 